\title{
KEANEKARAGAMAN JENIS TUMBUHAN PAKU TERESTRIAL DI KAWASAN HUTAN DENGAN TUJUAN KHUSUS (KHDTK) BANTEN
}

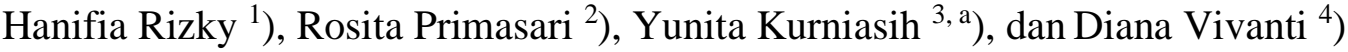 \\ 1, 2,3,4) Program Studi Magister Pendidikan Biologi, Universitas Negeri Jakarta, \\ Jl. Rawamangun Muka, Jakarta Timur, Indonesia 13220 \\ a) Email : yunitaita14@gmail.com
}

\begin{abstract}
Abstrak
Penelitian ini bertujuan untuk mengetahui jenis-jenis tumbuhan paku terestrial yang ada di KHDTK (Kawasan Hutan dengan Tujuan Khusus), besarnya frekuensi dan frekuensi relatif tumbuhan paku terestrial, dominansi dan dominansi relatif tumbuhan paku terestrial, indeks nilai penting dari tumbuhan paku terestrial, dan indeks dominansi tumbuhan paku terestrial. Metode penelitian yang digunakan adalah metode deskriptif dengan teknik purposive sampling dengan melihat komposisi jenis dan jumlah tumbuhan paku pada suatu area tertentu. Penelitian ini digunakan untuk mendeskripsikan keanekaragaman jenis paku yang ada di KHDTK (Kawasan Hutan Dengan Tujuan Khusus), Pandeglang, Banten. Pengamatan terhadap kondisi lingkungan meliputi intensitas cahaya, suhu lingkungan, kelembaban lingkungan, $\mathrm{pH}$ tanah, dan ketinggian tempat. Hasil penelitian yang diperoleh adalah ditemukannya tiga spesies paku pada KHDTK, yaitu Selaginella plana, Lygodium salicifolium, dan Diplazium esculentum. INP tertinggi terdapat pada spesies Selaginella plana dan terendah terdapat pada Diplazium esculentum. Selaginella plana lebih dominan dibandingkan spesies lainnya yaitu Lygodium salicifolium dan Diplazium esculentum.
\end{abstract}

Kata Kunci: Keanekaragaman jenis, Tumbuhan paku, Paku Selaginella plana

\begin{abstract}
This study aims to determine the types of terrestrial ferns that exist in KHDTK (Kawasan Hutan Dengan Tujuan Khusus), the frequency and relative frequency of terrestrial ferns, the relative dominance and dominance of terrestrial ferns, the important value index of terrestrial ferns, and the dominance index of terrestrial ferns. The research method used was descriptive method with purposive sampling technique by looking at the composition of species and number of ferns in a particular area. This study was used to describe the species diversity of ferns in KHDTK (Kawasan Hutan Dengan Tujuan Khusus), Pandeglang, Banten. Observations on environmental conditions include light intensity, environmental temperature, environmental humidity, soil $\mathrm{pH}$, and altitude. The results of the research obtained were the discovery of three species of ferns in KHDTK, namely Selaginella plana, Lygodium salicifolium, and Diplazium esculentum. The highest INP is found in Selaginella plana and the lowest is found in Diplazium esculentum. Selaginella plana is more dominant than other species namely Lygodium salicifolium and Diplazium esculentum.
\end{abstract}

Keywords: Species diversity, Pterydophyta, Selaginella plana

\section{Pendahuluan}

Indonesia merupakan negara kepulauan dengan berbagai macam jenis hutan yang tersebar disetiap dataran dan kepulauan. Indonesia adalah salah satu negara yang memiliki kekayaan flora terbesar di dunia dengan keanekaragaman hayati tertinggi di dunia setelah Brasilia. Salah satu kekayaan yang dimiliki adalah kawasan konservasi alam KHDTK (Kawasan Hutan Dengan Tujuan Khusus). Kronologis penataan dan pengelolaan
KHDTK Carita diawali pada tahun 1915 yang merupakan kompleks hutan Gunung Aseupan yang ditunjuk sebagai kawasan hutan. Kemudian tahun 1938 Kawasan Carita dijadikan sebagai hutan wisata. Tahun 1955 Balai Penyelidikan Kehutanan Bogor menggunakannya sebagai lokasi riset dan dilakukan pembangunan koleksi pohon famili dipterocarpaceae. Tahun 1978 kawasan hutan pantai Carita ditunjuk sebagai Taman Wisata Alam (TWA). Tahun 1990 pemberian hak penge- 
lolaan pariwisata alam kepada Perum Perhutani. Tahun 1993 penunjukan beberapa lokasi di kawasan hutan sebagai kebun percobaan dan pos penelitian pada kawasan yang dikelola Perum Perhutani. Tahun 1995 penetapan blok pengelolaan TWA Carita seluas $30 \mathrm{Ha}$ menjadi blok pemanfaatan dan sisanya merupakan blok perlindungan. Barulah 2003 penunjukan Kawasan Hutan dengan Tujuan Khusus (KHDTK) seluas \pm 3.000 ha. Tahun 2006 penataan batas KHDTK Hutan Penelitian Carita oleh BPKH XI Yogyakarta.

KHDTK yang memiliki wilayah konservasi alam salah satunya berada di provinsi Banten. Penetapan kawasan ini disetujui di Banten pada 7 Maret 2012. Pembentukannya berdasarkan UU nomor 5 tahun 1990, tentang konservasi sumber daya alam hayati dan ekosistemnya. KHDTK adalah kawasan pelestarian alam yang memiliki potensi keanekaragaman hayati seperti koleksi tumbuhan, satwa alami atau bukan alami, jenis asli maupun bukan asli yang dimanfaatkan sebagai media pendidikan, penelitian dan pengembangan ilmu pengetahuan. Selain itu kawasan ini dapat dijadikan objek pariwisata dan rekreasi. KHDTK yang kini menjadi objek wisata banyak dikunjungi oleh wisatawan baik lokal maupun nasional. Banyaknya pengunjung inilah yang menjadi salah satu kekhawatiran adanya pencemaran dan eksploitasi terhadap kawasan konservasi tersebut.

KHDTK yang terletak di Kabupaten Pandeglang-Banten ini termasuk kawasan hutan tropis yang terletak di dataran rendah dan berdekatan dengan laut, sehingga memiliki flora dan fauna yang khas. Wilayah konservasi seluas 1596 hektar ini perlu dijaga kelestariannya. Hutan secara umum dikenal sebagai suatu sumber daya yang memberi manfaat bagi kehidupan dimana proses interaksi antara berbagai komponen biotik dan abiotik di dalamnya bersifat saling ketergantungan. Salah satu jenis vegetasi yang melimpah pada kawasan KHDTK adalah tumbuhan paku terestrial. Paku terestrial merupakan tumbuhan paku yang tumbuh dan hidup di atas tanah terutama di lingkungan yang lembab seperti di KHDTK Pandeglang-Banten yang curah hujannya mencapai $2.853 \mathrm{~mm} /$ tahun.

Tumbuhan paku merupakan jenis tumbuhan yang dapat dijumpai di hutan topis. Sastrapraja dalam Musriadi (2017) menyatakan bahwa setiap jenis tumbuhan paku memerlukan kondisi lingkungan yang sesuai untuk tempat hidupnya. Tumbuhan ini hidup subur dan banyak dijumpai pada lingkungan yang lembab dan beriklim tropis. Meskipun hanya suatu kelompok kecil tumbuhan, namun memiliki peranan yang penting dalam pencirian tipe hutan tropis. Peranan pentingnya yaitu dalam pembentukan humus, melindungi tanah dari erosi, menjaga kelembaban tanah dan memiliki nilai ekonomi yang cukup tinggi terutama pada keindahannya sebagai tanaman hias. Tumbuhan paku juga mempunyai nilai ekologis sebagai tumbuhan bawah yang berperan dalam menjaga berlangsungnya ekosistem hutan seperti pencampuran serasah bagi pembentukan hara tanah serta sebagai vegetasi penutup tanah karena merupakan tumbuhan bawah dan mencegah terjadinya erosi serta produsen dalam rantai makanan (Luthfiya, 2013).

Faktor lingkungan yang mempengaruhi pertumbuhan paku yaitu suhu, intensitas cahaya, kelembaban tanah dan udara, dan $\mathrm{pH}$ tanah atau keasaman tanah. Suhu merupakan faktor yang penting karena menentukan kecepatan reaksi-reaksi dan kegiatan kimia dalam proses kehidupan. Suhu dapat berbeda di setiap wilayah karena adanya perbedaan tinggi rendahnya intensitas penyinaran matahari yang bergantung pada sudut datang sinar matahari, letak lintang, jarak atau lokasi daratan terhadap laut, ketinggian tempat, dan penutupan lahan oleh vegetasi. Menurut Lubis (2009) rendahnya intensitas cahaya dipengaruhi oleh ada tidaknya tutupan tajuk dan awan. Menurut LIPI (1980) Paku di hutan umumnya merupakan paku yang menyukai naungan. Paku di hutan terlindung dari panas dan angin kencang sehingga intesitas cahayanya kurang dan kelembaban tinggi, dimana kondisi seperti ini sesuai dengan habitat tumbuhan paku yang menyukai kelembaban. Intensitas cahaya yang terlalu rendah akan membatasi fotosintesis dan menyebabkan cadangan makanan cenderung lebih banyak dipakai daripada disimpan. Pada intensitas cahaya yang tinggi kelembaban udara berkurang, sehingga proses transpirasi berlangsung lebih cepat (Treshow, 1970).

Tumbuhan paku sampai saat ini masih kurang mendapat perhatian dibandingkan dengan kelompok jenis tumbuhan lain meskipun sebenarnya tumbuhan ini memiliki fungsi bagi kesejahte- 
raan makhluk hidup. Berdasarkan habitatnya pa$\mathrm{ku}$ dibagi menjadi paku terestrial, epifit, dan akuatik. Paku terestrial habitatnya berada di atas tanah. Sebagai salah satu hutan hujan tropis, KHDTK Pandeglang-Banten sangat cocok untuk pertumbuhan paku terestrial.

Berdasarkan paparan di atas, maka perlu dilakukan kajian khusus mengenai paku terestrial. Kajian ini digunakan untuk mengidentifikasi jenis, frekuensi, dominansi, indeks nilai penting (INP), dan indeks keanekaragaman dari jenis tumbuhan paku terestrial. Penelitian ini dilakukan unuk mengumpulkan data mengenai berbagai jenis tumbuhan paku yang terdapat di KHDTK (Kawasan Hutan dengan Tujuan Khusus) Pandeglang Banten. Hasil dari pengambilan data ini diharapkan menjadi dorongan positif untuk membangun daerah ekowisata tumbuhan paku terestrial di KHDTK pada waktu yang akan datang.

\section{Metode Penelitian}

Penelitian ini menggunakan metode deskriptif dengan teknik purposive sampling dengan melihat komposisi jenis dan jumlah tumbuhan paku pada suatu area tertentu. Pengamatan terhadap kondisi lingkungan meliputi intensitas cahaya, suhu lingkungan, kelembaban lingkungan, $\mathrm{pH}$ tanah, dan ketinggian tempat. Tumbuhan paku yang ditemukan dilakukan koleksi data dengan pembuatan herbarium, identifikasi tumbuhan spesimen, dan analisis data yang meliputi (1) Perhitungan frekuensi; (2) Dominansi; (3) Perhitungan INP; dan (4) Perhitungan indeks dominansi.

\section{Hasil dan Pembahasan}

Penelitian di KHDTK (Kawasan Hutan dengan Tujuan Khusus) mendapatkan data berupa parameter abiotik dan biotik. Parameter abiotik yang diukur adalah faktor ketinggian, suhu, $\mathrm{pH}$ tanah, dan intensitas cahaya matahari. Parameter biotik yang didapatkan adalah jenis dan keanekaragaman paku. Tabel 4.1 menyajikan hasil pengukuran parameter abiotik.

\begin{tabular}{|c|c|c|c|c|c|c|}
\hline \multirow[t]{2}{*}{ No } & \multirow[t]{2}{*}{ Parameter } & \multicolumn{4}{|c|}{ Ketinggian (m) } & \multirow{2}{*}{$\begin{array}{l}\text { Rata- } \\
\text { rata }\end{array}$} \\
\hline & & 23 & 20 & 14 & 8 & \\
\hline 1 & Suhu $\left({ }^{0} \mathrm{C}\right)$ & 21 & 20,7 & 21,3 & 21 & 21 \\
\hline 2 & $\mathrm{pH}$ tanah & 6,8 & 7 & 6,8 & 7 & 6,9 \\
\hline 3 & Intensitas & 1340 & 1360 & 1450 & 19 & 1532 \\
\hline & cahaya & $\operatorname{lux}$ & $\operatorname{lux}$ & $\operatorname{lux}$ & 80 &, 5 \\
\hline
\end{tabular}

Hasil penelitian selanjutnya berupa pengukuran yang dilakukan dengan cara menghitung frekuensi mutlak, frekuensi relatif, dominansi mutlak, dominansi relatif, INP, dan indeks dominansinya. Hasil pengukuran tersebut ditunjukkan pada tabel 2 berikut ini.

Tabel 2. Perhitungan Frekuensi Relatif, Dominansi Relatif, INP, Indeks Dominansi

\begin{tabular}{|c|c|c|c|c|c|c|c|}
\hline No & Spesies & FM & FR & $\begin{array}{l}\mathrm{D} \\
\mathrm{M}\end{array}$ & $\begin{array}{l}\mathrm{D} \\
\mathrm{R}\end{array}$ & $\begin{array}{l}\text { INP } \\
(\%)\end{array}$ & $\mathrm{C}$ \\
\hline 1 & $\begin{array}{l}\text { Selagin } \\
\text { ella } \\
\text { plana }\end{array}$ & 0,65 & $\begin{array}{c}48 \\
15\end{array}$ & $\begin{array}{c}1,4 \\
4\end{array}$ & $\begin{array}{l}83, \\
07\end{array}$ & $\begin{array}{c}131, \\
22\end{array}$ & $\begin{array}{c}0,4 \\
3\end{array}$ \\
\hline 2 & $\begin{array}{l}\text { Lygodi } \\
\text { um } \\
\text { salicifo } \\
\text { lium }\end{array}$ & 0,65 & $\begin{array}{c}48 \\
15\end{array}$ & $\begin{array}{c}0,2 \\
4\end{array}$ & $\begin{array}{l}14, \\
01\end{array}$ & $\begin{array}{c}62,1 \\
5\end{array}$ & $\begin{array}{l}0,0 \\
96\end{array}$ \\
\hline 3 & $\begin{array}{l}\text { Diplazi } \\
\text { um } \\
\text { esculen } \\
\text { tum }\end{array}$ & 0,05 & $\begin{array}{c}3,2 \\
3\end{array}$ & $\begin{array}{c}0,0 \\
5\end{array}$ & $\begin{array}{c}2,9 \\
3\end{array}$ & 6,63 & $\begin{array}{c}0,0 \\
01\end{array}$ \\
\hline & Jumlah & 1,35 & & $\begin{array}{c}1,7 \\
3\end{array}$ & & & $\begin{array}{l}0,5 \\
28\end{array}$ \\
\hline
\end{tabular}

Keterangan :

$$
\begin{array}{ll}
\text { FM } & =\text { Frekuensi mutlak } \\
\text { FR } & =\text { Frekuensi relatif } \\
\text { DM } & =\text { Dominansi mutlak } \\
\text { DR } & =\text { Dominansi relatif } \\
\text { INP } & =\text { Indeks Nilai Penting } \\
\text { C } & =\text { Indeks Dominansi }
\end{array}
$$

Kriteria indeks dominansi dibagi dalam 3 kategori, yaitu : $0,01-0,30=$ dominansi rendah

$0,31-0,60=$ dominansi sedang $0,61-1,0=$ dominansi tinggi

\section{Identifikasi jenis tumbuhan paku}

Tumbuhan paku yang ditemukan pada KHDTK berjumlah tiga jenis, yaitu paku Rane (Selaginella plana), paku Hatta (Lygodium Salicifolium), dan paku Diplazium esculentum. Deskripsi dari masing-masing jenis paku tersebut dijelaskan sebagai berikut :

\section{Paku Rane (Selaginella plana)}

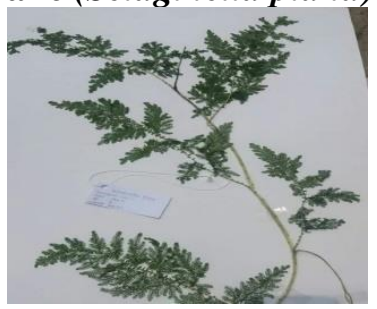
Klasifikasi Ilmiah
Kingdom : Plantae
Divisi : Lycopodiophyta
Kelas : Isoetopsida
Ordo : Selaginellales 
Famili : Selaginellaceae

Genus : Selaginella

Spesies : Selaginella plana

\section{Deskripsi}

Paku Rane (Selaginella) adalah marga sekelompok tumbuhan berpembuluh yang merupakan satu-satunya anggota suku Selaginellaceae. Tumbuhan ini berkembang biak dengan spora bebas, sehingga dianggap sebagai bagian dari tumbuhan paku (Pteridophyta).

Rane memiliki ciri daun kecil dan sederhana (disebut mikrofil) yang menyerupai sisik pipih dan duduk (tidak bertangkai), serta heterosporik (menghasilkan dua tipe spora yang berbeda ukurannya). Pertumbuhan cabang dan daunnya tidak berupa gulungan membuka seperti paku sejati, sehingga memang sebenarnya rane dan kumpai bukanlah tumbuhan paku.

Habitat Selaginella plana ini tumbuh pada batu-batuan atau tebing sungai, menyukai kelembapan. Rimpangnya menjalar pada permukaan batuan dan akar-akarnya masuk ke celah-celah batu. Habitus pada Selaginella ini yaitu perdu yang mana mempunyai ciri-ciri pendek, berkayu, mempunyai percabangan langsung dan biasanya tinggi di atas permukaan tanah sekitar $1 \mathrm{~m}$.

\section{Paku Hatta (Lygodium salicifolium )}

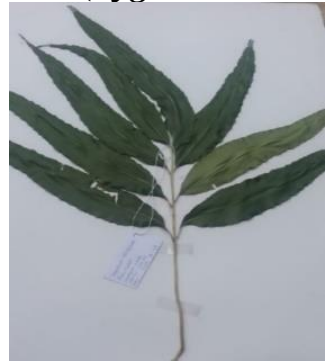

Gambar 2. Lygodium salicifolium

\section{Klasifikasi Ilmiah}

Kingdom : Plantae

Divisi : Pteridophyta

Kelas : Filicinae

Ordo : Filicales

Famili : Schizaceae

Genus : Lygodium

Spesies : Lygodium salicifolium

\section{Deskripsi}

Secara umum Lygodium mempunyai akar yang merayap, berambut tapi tidak bersisik. Daun-daunnya monostichous, melilit dan pertum- buhannya tidak dapat didefinisikan. Rantingnya biasanya tidak panjang, ranting primernya pendek, ujungnya terhenti dan ditutupi oleh rambut dan setiap ujungnya terdapat sepasang ranting sekunder. Ranting sekunder mengandung daun dengan bentuk menyirip, atau cabang dikotom mengandung daun yang bercuping. Terdapat pula daun yang steril berbentuk gerigi maupun berlobus, sedangkan daun yang fertil menjuntai sepanjang tepinya dengan cuping sempit yang pendek dan setiap cuping mengandung dua baris sporangia yang ditutupi dengan indusium kecil.

Menurut LIPI (1980), bahwa kebanyakan Lygodium tumbuh di daerah terbuka dan disinari matahari. Menurut Holttum (1963), Lygodium tumbuh di hutan sekunder, atau memanjat pada tumbuhan berpohon di daerah terbuka. Kramer (1990) menyatakan bahwa distribusi Lygodium adalah India, Cina bagian selatan, Malaysia sampai Australia, di Malaya dapat dijumpai dimanapun pada daerah dataran rendah dan tempat terbuka.

3. Paku Diplazium esculentum

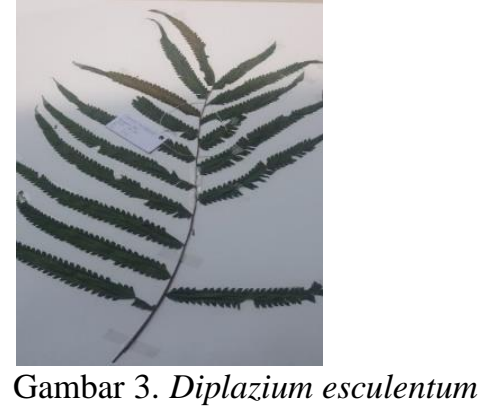

Klasifikasi Ilmiah

Kingdom : Plantae

Divisi : Pteridophyta

Kelas : Pteridopsida

Ordo : Polypodiales

Famili: Polypodiaceae

Genus: Diplazium

Spesies: Diplazium esculentum

\section{Deskripsi}

Kelompok kami menemukan Diplazium dijalan jalur track KHDTK. Diplazium sebagian besar merupakan genus tropis, di Amerika utara hanya tiga spesies seperti Diplazium pycnocarpon. Diplazium salah satu termasuk dalam atrium dan asplenium. umumnya alternatif nama dimasukkan berasal dari sebelum asplenium (boughton,2005). Diplazium merupakan tumbuhan paku berdaun 
majemuk, tumbuh tidak merambat, sorus berbentuk cincin yang mengikuti tepi daun.

Diplazium tumbuh di daerah pegunungan yang ketingiannya sekitar $1.350 \mathrm{~m}$. Oleh karenanya banyak terdapat di gunung arjuna dan gunung patuha (Setijati Sastrapradja, 1985). Termasuk di Taman Alam Los Alcornocales, yang berlangsung sebuah habitat yang sama ke hutan salam, hangat dan lembab sepanjang tahun (Joan Bibiloni, 2011).

Daun paku : tinggi $100 \mathrm{~cm}$ sebesar $20 \mathrm{~cm}$, agak dimorfik, daun subur lebih tinggi, tegak, steril melengkung. Stipe: cokelat kemerahan pada pangkal, ke atas hijau, sangat beralur, beberapa sisik dekat pangkalan, bersatu untuk bentuk-v di atas. Pinnae: 20 sampai 40 pasangan, costae beralur terus menerus dari malai ke costae. Sori: linier sedikit melengkung, indusiumnya linier sedang sporangia hitam (Broun, 2011).

Hasil pengukuran parameter suhu menunjukkan bahwa rata-rata suhu di KHDTK $21^{\circ} \mathrm{C}$. Suhu $21-27^{\circ} \mathrm{C}$ merupakan suhu optimal untuk pertumbuhan paku yang hidup didaerah tropis (Katili, 2013). Berdasarkan hasil tersebut tumbuhan paku dapat tumbuh dengan baik, namun faktanya spesies yang ditemukan sedikit. Suhu udara yang semakin meningkat akan menyebabkan dominansi jenis paku terutama Selaginella plana semakin menurun (Sutomo dan Dini, 2013). Setyawan (2009) menyatakan bahwa sebagian besar masyarakat di Nusantara mengetahui bahwa jenis paku Selaginella plana biasanya terdapat pada lokasi yang lembab, basah, dan juga ditemukan di dekat jurang atau dekat tebing yang curam. Hal lainnya dikarenakan terdapat tumbuhan yang lebih dominan yaitu Shorea leprosulla yang termasuk dalam kelompok dipterocarpacea berupa anakan pohon, sehingga pertumbuhan paku menjadi terhambat. Tumbuhan dipterocarpacea sengaja dikonservasi karena jumlahnya yang semakin sedikit pada kawasan KHDTK.

Rata-rata intensitas cahaya matahari hasil pengukuran menunjukkan angka yang cukup tinggi yaitu 1532,5 lux. Sehingga jumlah paku yang ditemukan di KHDTK sedikit karena menurut LIPI (1980) paku di hutan lebih menyukai naungan, terlindung dari panas dan angin kencang, intesitas cahaya kurang, dan kelembaban tinggi.
Adanya perbedaan jumlah jenis tumbuhan paku terestrial yang ditemukan pada suatu daerah dipengaruhi oleh kondisi lingkungan tempat tumbuh (Soerianegara dan Indrawan, 1967). Menurut Badan Litbang Kehutanan (2005) jenis tanah di KHDTK adalah aluvial kelabu dengan bahan induk endapan liat. Secara umum sifat fisik tanah aluvial adalah tekstur liat, struktur pejal, konsistensi teguh (lembab), plastis (basah), keras (kering), warna kelabu hingga coklat. Sehingga kondisi tersebut kurang cocok untuk pertumbuhan paku pada umumnya.

Pada kawasan KHDTK Banten yang intensitas cahayanya cukup tinggi ditumbuhi oleh tumbuhan paku dengan perawakan yang relatif rendah, seperti Selaginella plana. Sutrisna (1981) menyatakan bahwa faktor lingkungan dan kemampuan beradaptasi terhadap suatu habitat akan mempengaruhi jumlah jenis yang ditemukan pada suatu kawasan. Keberadaan tumbuhan paku di suatu tempat dipengaruhi oleh faktor lingkungan, yang meliputi faktor biotik maupun abiotik. Faktor biotik yang mempengaruhi pertumbuhan paku adalah kompetisi antara tumbuhan paku itu sendiri untuk mendapatkan makanan atau tempat hidupnya. Faktor-faktor abiotik yang mempengaruhi tumbuhan paku adalah iklim (suhu udara, kelembaban udara, intensitas cahaya), tanah dan kondisi fisik lingkungan lainnya (Katili 2014).

Hasil perhitungan menunjukkan bahwa tumbuhan paku terestrial yang memiliki INP tertinggi adalah Selaginella plana. Ini menunjukkan bahwa tingkat penguasaan Selaginella plana terhadap komunitas dan lingkungannya tinggi sehingga dapat mempengaruhi kestabilan ekosistem (Fachrul, 2007). Selaginella plana ditemukan hampir diseluruh plot dengan frekuensi jenis yang tinggi dan dominansi yang besar. Hal ini dikarenakan Selaginella plana bersifat kosmopolitan dan dapat tumbuh di berbagai jenis iklim dan tanah (Setyawan, Ahmad Dwi, 2011). Selaginella plana juga memiliki akar rhizom dan berfungsi sebagai penutup tanah (Sastrapradja, et.al, 2002). INP tertinggi kedua adalah Lygodium salicifolium karena sebagian besar anggota dari Famili Lygodiaceae hidup di tempat-tempat yang terbuka sehingga mudah ditemukan dan merupakan famili tumbuhan paku yang hidup di daerah dataran rendah dan dataran tinggi (Holtum, 1967). 
Indeks dominansi menyatakan tingkat terpusatnya dominansi (penguasaan) jenis dalam suatu komunitas (Indriyanto 2006). Berdasarkan hasil perhitungan, indeks dominansi didapatkan sebesar 0,528 yang artinya indeks dominansi sedang. Hal ini mengindikasikan bahwa spesies tumbuhan tertentu yaitu Selaginella plana pada lokasi penelitian lebih dominan dibandingkan spesies lainnya. Kusmana dan Istomo (1997) menyatakan bahwa semakin tinggi tingkat dominansi maka semakin sedikit keanekaragamannya. Sehingga dapat disimpulkan bahwa keanekaragaman paku terestrial di KHDTK sedikit atau rendah.

\section{Kesimpulan dan Saran}

Spesies paku yang ditemukan pada KHDTK Banten berjumlah 3 spesies, yaitu Selaginella plana, Lygodium salicifolium, dan Diplazium esculentum. INP tertinggi terdapat pada spesies Selaginella plana dan terendah terdapat pada Diplazium esculentum. Selaginella plana lebih dominan dibandingkan spesies lainnya yaitu Lygodium salicifolium dan Diplazium esculentum.

Penelitian lanjutan dapat dilaksanakan dengan menambah jumlah plot yang digunakan. Selain itu, penelitian dapat dilakukan di tempat yang mirip kondisi biografisnya.

\section{Daftar Pustaka}

Diah Irawati. (2012). Keragaman Jenis Tumbuhan Paku (Pterydophyta) Di Cagar Alam Gunung Ambang Sulawesi Utara. BPK Manado, 2 (1), 8-21.

Dinas Kehutanan dan perkebunan Banten. https:// dishutbun.bantenprov.go.id/read/articledetail/headline/92/taman-hutan-rayatahura-banten.html. (Diakses pada $26 \mathrm{Ju}-$ ni 2018 Pukul 13.00 WIB).

Holtum, RE., (1967). Flora of Malaya vol II (fern of malaya), Government Printing office, Singapore.

Indah, N. (2009). Taksonomi Tumbuhan Tingkat Rendah. Jember: Fakultas MIPA IKIP PGRI JEMBER Jurusan Biologi. Tidak Diterbitkan.

Indriyanto. (2006). Ekologi Hutan. Jakarta: PT Bumi Aksara.

Istomo, Kusmana C. (1997). Penuntun Praktikum Ekologi Hutan. Bogor : Laboratorium
Ekologi Hutan. Bogor: Fakultas Kehutanan. Institur Pertanian Bogor.

Jamsuri. (2007). Keanekaragaman Tumbuhan Paku Di Sekitar Curug Cikaracak Bogor Jawa Barat. Skripsi UIN Syarif Hidayatullah: Jakarta.

Katili, A.S. (2013). Deskripsi Pola Penyebaran Dan Faktor Bioekologis Tumbuhan Paku (Pteridophyta) Di Kawasan Cagar alam Gunung Ambang Sub Kawasan Kabupaten Bolaang Mongondow Timur. Sainstek $7(2)$.

Kusumaningrum, B.D. (2008). Analisis Vegetasi Epifit di Area Warna Wisata Gonoharjo Kabupaten Kendal Provinsi Jawa Tengah. IKIP PGRI. Semarang.

Lindasari, Weri Febri dkk. (2015). Jenis-Jenis Paku Epifit di Hutan Desa Beginjan Kecamatan Tayan Hilir Kabupaten Sanggau. Jurnal Protobiont, 4 (3), 65-73.

LIPI. (1980). Jenis-Jenis Paku di Indonesia. Bogor : Lembaga Biologi Nasional.

Lubis, Siti Rahma. (2009). Keanekaragaman dan Pola Distribusi Tumbuhan Paku di Hutan Wisata Alam Taman Eden Kabupaten Toba Samosir Provinsi Sumatera Utara. Sekolah PascaSarjana Universitas Sumatera Utara Medan (tesis). Tidak terbitkaan (online).

Luthfiya, Z.N., Liza, N.,Putri, R.D.A \& Sugiyarto. (2015). Keanekaragaman Tumbuhan Paku (Pteriodphyta) Di Kawasan Lereng Barat Gunung Lawu. Prosiding. Jawa Tengah : Universitas Sebelas Maret.

Maulidia, Adinda, dkk. (2017). Keanekaragaman Tanaman Paku (Pteridophyta) di Jalur Ciwalen Taman Nasional Gunung Gede Pangrango Jawa Barat. Jurnal Biosfer. Jakarta: Universitas Negeri Jakarta. 2(2).

Michael, P. (1984). Ecologycal System Metode for File and Laboratory Investigations. New Delhi: Tata Mcgraw-Hill Publishing Company Limited.

Musriadi, Jailani dan Armi. (2017). Identifikasi Tumbuhan Paku (Pteridophyta) Sebagai Bahan Ajar Botani Tumbuhan Rendah Di Kawasan Tahura Pocut Meurah Intan Kabupaten Aceh Besar. Jurnal Pendidikan Sains Universitas Muhammadiyah Semarang. 5(1). 
Nybakken, J.W. (1992). Biologi Laut: Suatu Pendekatan Ekologis. Cetakan ke 2. Terjemahan H.M. Eidman, Koesoebiono, D.G. Bengen M. Hutomo \& S. Sukoharjo. Jakarta: PT Gramedia Pustaka Utama.

Pesona Keindahan Wisata Taman Hutan Raya (Tahura) di Carita Pandeglang Banten. https://www.teluklove.com/2017/03/peso na-keindahan-wisata-taman-hutan.html. (Diakses pada 26 Juni 2018 Pukul 13.00 WIB).

Sastrapradja, S., J.J Afriastini, D. Darnaedi, and E.A Widjaja. (2002). Jenis Paku Indonesia. Lembaga Biologi NasionalLIPI, Bogor. 129 p.

Sastrapradja, S,. J.J. Afriastini. (1985). Kerabat Paku. Bogor: Lembaga Biologi Nasional, Sri Sumber Daya Alam, Lembaga Ilmu Pengetahuan Indonesia.

Setyawan, Ahmad Dwi. (2011). Review: Recent Status Of Selaginella (Selaginellaceae) Research In Nusantara. Biodiversitas. 12 (2), Pages: 112-124, Issn: 2085-4722, Doi: 10.13057/Biodiv/D120209.

Setyawan, A.D. (2009). Traditionally utilization of Selaginella: field research and litera- ture review. Nusantara BIOSCIENCES $1,146-158$.

Soerianegara I dan A Indrawan. (2008). Ekologi Hutan Indonesia. Bogor : Laboratorium Ekologi Hutan Fakultas Kehutanan Institut Pertanian Bogor.

Sutomo dan Dini Fardila. (2013). Autekologi Tumbuhan Obat Selaginella Doederleinii Hieron Di Sebagian Kawasan Hutan Bukit Pohen Cagar Alam Batukahu, Bedugul Bali. Jurnal Penelitian Hutan Dan Konservasi Alam. 10 (2).153-161

Syamsiah. (2009). Identifikasi Jenis-Jenis Tumbuhan Lumut (Bryophyta) Di Kawasan Wisata Air Terjun Takapala Malino. Jurnal Seminar Hasil Penelitian. Makasar: Universitas Negeri Makasar.

Treshow,M. (1970). Environtment and Plant Respont. Mc Graw Hill Company, New York.

Wahyu, Suwasono, Agung. (2015). Identifikasi Tumbuhan Paku Epifit Pada Batang Kelapa Sawit Di Lingkungan Universitas Brawijaya. Jurnal Produksi Tanaaman. 3(1). 6574

Yudianto, Suroso. (1991). Pengantar Cryptogamae. Bandung: Pen. Tarsit 